\title{
Antibacterial activity of Ampicillin trihydrate formulated in Aluminium-Magnesium Silicate, against Salmonella gallinarum
}

\author{
Maduike C. O. Ezeibe*, George N. Anosa, Okechi K. Okorie, Nnenna P. Elendu-Eleke, \\ Obianuju N. Okoroafor, Augustine A. Ngene, Ogechukwu N. Chikelu \\ Department of Veterinary Medicine, University of Nigeria, Nsukka, Nigeria; *Corresponding Author: maduikeezeibe@yahoo.com
}

Received 14 June 2012; revised 13 July 2012; accepted 25 July 2012

\begin{abstract}
To test if stabilizing Ampicillin trihydrate (AT) with Aluminium-Magnesium Silicate (AMS) can enhance its antibacterial activities, different concentrations of AT solution and of a formulation of AT in the AMS, were made and used for sensitivity test on Salmonella gallinarum cultures. Also, S. gallinarum-infected chicks were treated with; $10 \mathrm{mg} / \mathrm{Kg}$ (AT), $10 \mathrm{mg} / \mathrm{Kg}$ (AT in AMS), 7.5 $\mathrm{mg} / \mathrm{Kg}$ (AT), $7.5 \mathrm{mg} / \mathrm{Kg}$ (AT in AMS). Mean diameter of inhibition zone, $28.39 \pm 2.07 \mathrm{~mm}$ produced by AT did not vary significantly $(P>0.05)$ from $26.36 \pm 2.05 \mathrm{~mm}$ produced by AT in AMS. However, mean Salmonella gallinarum culture forming units per $\mathrm{ml}$ of bile, $17.6 \pm 11 \times 10^{5}$ of the untreated chicks and $3.4 \pm 0.81 \times 10^{5}(80.58 \%$ reduction), $2.4 \pm 0.67 \times 10^{5}$ (85.70\% reduction), $5.4 \pm 1.93 \times 10^{5}(69.20 \%$ reduction $)$ and $0.38 \pm$ $0.13 \times 10^{5}(97.80 \%$ reduction ) of the respective treated groups, showed AMS significantly $(P<$ 0.01 ) improved AT's ability to clear $S$. gallinarum infection, in vivo.
\end{abstract}

Keywords: Antibiotic Resistance; Synthetic Aluminium-Magnesium Silicate; Stabilization; Salmonella gallinarum

\section{INTRODUCTION}

Salmonellosis (typhoid fever) is still a leading human health challenge in the world. In the year, 2000 alone, typhoid fever caused over 216,500 human deaths [1]. Though incidence of salmonellosis in humans is highest in less developed countries of Asia, Africa and Latin America [2], it is still a public health concern even in the USA [3]. It is a zoonosis and leads to condemnation of meat at meat inspection. So, it is a concern both for pub- lic health and as a cause of loss of investment to livestock farmers and to meat processing factories [4].

Development of resistance by bactria to antibiotics often results if the antibiotics fail to ellinate the bacterial infections [5]. For Ampicillin, its antibacterial activity depends on its bioavailability and on length of time it is able to maintain high concentration in blood of treated animals [6]. Differences in therapeutic actions of drugs made from same medicinal active ingredients but manufactured by different companies are reported to be due to interactions of components used in formulating the drugs and on stabilizing agents used [7].

Alluminium-Magnesium Silicate (AMS) is used as a stabilizing agent for drugs used for treatment of diseases of man and of animals [8,9]. It is safe for use even on food animals [10] and was also decleared safe in a recent assessment that involved topical and oral administration to laboratory animals [11]. Its molecules have one of their ends positively charged and the other negatively charged [9]. These electrical charges make AMS, when in solution, to hydrate to form three dimentional coloidal structures which stabilize drugs' active ingredients [9].

To stabilize means to protect against destruction. So, if AMS is used to make a formulation of Ampicillin trihydrate (AT), it may protect the antibiotic from being rapidly degraded by metabolic processes. If high concentration of AT is retained in blood of treated animals for a long time, it may lead to better clearance of Salmonella organisms. Enhanced bacterial clearance by antibiotics could reduce incidence of antibiotic resistance by bacteria, including the Salmonella species.

The natural AMS contains many impurities [9]. If it is used at doses higher than those currently employed, the impurities it contains could lead to adverse side effects on treated animals or humans. To overcome the problem of impurities in the natural AMS, we reacted Aluminium Silicate and Magnesium Silicate to get the synthetic AMS [12]. 


\section{MATERIAL AND METHODS}

One gramm of a drug formulation of 2.5\% AT in AMS and $0.1 \mathrm{~g}$ of AT powder were disolved in $1 \mathrm{ml}$ and in 4 $\mathrm{ml}$ of normal saline respectively, to obtain AT concentration of $25 \mathrm{mg} / \mathrm{ml}$ in each of the two solutions. The solutions were then, each, serially double diluted to get AT concentrations of $12.5 \mathrm{mg} / \mathrm{ml}, 6.25 \mathrm{mg} / \mathrm{ml}, 3.125 \mathrm{mg} / \mathrm{ml}$ and $1.5625 \mathrm{mg} / \mathrm{ml}$ for each of the two solutions. The five AT concentrations of each of the two solutions were then used for sensitivity test on pure cultures of S. gallinarum. Diameters of inhibition zones on replicate cultures tested, were measured and their means recorded as diameters of inhibition zone for each of the concentrations of AT in the two drug preparations. Mean inhibition zones' diameters for the AT and for the AT-AMS drug formulation were compared by the student T-test.

In the in vivo experiment, fifty chicks infected with $S$. gallinarum were randomly assigned into five groups. Two groups were treated, for five days, at dose rates of $10 \mathrm{mg}$ and $7.5 \mathrm{mg}$ of AT per Kg body weight respectively, with AT alone. Two other groups were similarly treated with the AT-AMS drug formulation while the fifth group served as control. Clinical signs and lessions of salmonellosis in the five groups were recorded. Also, bile of 5 chicks randomly sellected from each group were cultured. S. gallinarum colonies in each culture were counted under the microscope and expressed in units of 100,000 Culture Forming Units per $\mathrm{ml}\left(10^{5} \mathrm{CFU} / \mathrm{ml}\right)$ of bile. Means of the S. gallinarum $10^{5} \mathrm{CFU} / \mathrm{ml}$ of bile of the different treatment groups were compared for statistical differences, by Analysis of Variance.

\section{RESULTS}

Mean diameter of inhibition zone of $S$. gallinarum by AT achieved with the AT alone $(28.30 \pm 2.07 \mathrm{~mm})$ did not vary significantly $(P>0.05)$ from $26.36 \pm 2.05 \mathrm{~mm}$ achieved with the AT-AMS drug formulation. How-

Table 1. Zones of inhibition of Salmonella gallinarum, produced by Ampicillin-Aluminimum Magnesium Silicate drug formulation.

\begin{tabular}{ccc}
\hline $\begin{array}{c}\text { Ampicillin concentration } \\
(\mathbf{m g} / \mathbf{m l})\end{array}$ & \multicolumn{2}{c}{$\begin{array}{c}\text { Diameter of inhibition } \\
(\mathrm{mm})\end{array}$} \\
\hline $\mathbf{1 . 5 6}$ & Ampicillin & Ampicillin in AMS \\
$\mathbf{3 . 1 3}$ & 23.7 & 23.7 \\
$\mathbf{6 . 2 5}$ & 24.8 & 24.8 \\
$\mathbf{1 2 . 5 0}$ & 28.7 & 27.3 \\
$\mathbf{2 5 . 0 0}$ & 29.8 & 27.0 \\
Mean \pm SD & 34.5 & 29.0 \\
\hline
\end{tabular}

ever, mean Salmonella gallinarum titre of bile of the control chicks ( $\left.17.6 \pm 11 \times 10^{5} \mathrm{CFU} / \mathrm{ml}\right)$ varied significantly $(\mathrm{P}<0.05)$ from $3.4 \pm 0.81 \times 10^{5}, 2.4 \pm 0.67 \times 10^{5}$, $5.4 \pm 1.93 \times 10^{5}$ and $0.38 \pm 0.13 \times 10^{5}$ of those of the groups treated with $10 \mathrm{mg} / \mathrm{Kg}$ (AT), $10 \mathrm{mg} / \mathrm{Kg}$ (AT in AMS), $7.5 \mathrm{mg} / \mathrm{Kg}$ (AT) and $7.5 \mathrm{mg} / \mathrm{Kg}$ (AT in AMS) repectively. Rates of reduction of bacterial titres in the respective groups treated with AT powder and with the AT-AMS drug formulation respectively, were: with 10 $\mathrm{mg} / \mathrm{kg}, 80.58 \%$ and $85.70 \%(\mathrm{P}<0.05)$ and with 7.5 $\mathrm{mg} / \mathrm{kg}, 69.20 \%$ and $97.80 \%(\mathrm{P}<0.01)$ (Tables 1 and 2$)$.

There was no mortality in any of the groups, but greenish diarrhoae persisted in the untreated group while it ceased in all the treated chicks. Livers of the untreated chicks were congested, haemorrhagic and friable. Those of the group treated with $7.5 \mathrm{mg} / \mathrm{Kg} \mathrm{AT}$ alone had only congestion. The group treated with $10 \mathrm{mg} / \mathrm{Kg}$ AT in AMS had haemorrhagic livers. There was no gross lessions in the chicks treated with $10 \mathrm{mg} / \mathrm{Kg}$ AT alone and in those treated with $7.5 \mathrm{mg} / \mathrm{Kg}$ AT in AMS.

\section{DISCUSSION}

Detection of $S$. gallinarum infection titre of $17.6 \pm 11 \times$ $10^{5} \mathrm{CFU} / \mathrm{ml}$ in bile of chicks that were apparently healthy is of publichealth concern, because such infected chicken can be passed as wholesome for human consumption, at meat inspection.

AMS improved antibacterial action of AT both at 10 $\mathrm{mg} / \mathrm{Kg}$ and at $7.5 \mathrm{mg} / \mathrm{Kg}$. However, its effect at 7.5 $\mathrm{mg} / \mathrm{Kg}$ was significantly $(\mathrm{P}<0.01)$ better than its effect at the dose of $10 \mathrm{mg} / \mathrm{Kg}$. It is possible that by delaying degradation of AT, the AMS caused the normaly used dose of AT $(10 \mathrm{mg} / \mathrm{Kg})$ to become overdose and thus led to toxicity in treated chicks. Haemorhages on livers of those chicks treated with $10 \mathrm{mg} / \mathrm{Kg}$ AT in AMS while lessions were absent in chicks treated with $10 \mathrm{mg} / \mathrm{Kg}$ AT

Table 2. Salmonella gallinarum titre of bile of infected chicks treated with Ampicillin trihydrate-Aluminium Magnesium Silicate drug formulation.

\begin{tabular}{cccccc}
\hline Chicks & \multicolumn{5}{c}{ Colony forming units $\times 10^{5} / \mathrm{ml}$ of bile } \\
\hline \multicolumn{5}{c}{$10 \mathrm{mg} / \mathrm{kg}$} & $7.5 \mathrm{mg} / \mathrm{kg}$ \\
\cline { 2 - 6 } & Ampicillin Amp-AMS & Ampicillin & Amp-AMS & Control \\
\hline 1 & 5 & 2 & 4 & 0.2 & 31 \\
2 & 2 & 1 & 4 & 0.1 & 32 \\
3 & 4 & 1 & 9 & 0.2 & 8 \\
4 & 1 & 4 & 2 & 0.7 & 9 \\
5 & 5 & 4 & 8 & 0.7 & 8 \\
Mean & $3.4 \pm 0.81$ & $2.4 \pm 0.67$ & $5.4 \pm 1.93$ & $0.38 \pm 0.13$ & $17.6 \pm 0.11$
\end{tabular}


alone, even when that group of $10 \mathrm{mg} / \mathrm{kg}$ AT alone had higher CFU/ml, supports the suggestion that toxicity, and not Salmonella infection, caused the relative reduction in effect of the AMS on AT at dose of $10 \mathrm{mg} / \mathrm{kg}$ (Figure 1).

That $10 \mathrm{mg} / \mathrm{Kg}$ of AT alone, which is the recomended dose of AT, achieved only $80.58 \%$ reduction of the bacterial titre may be one of the causes of antibiotic resistance against the drug by Salmonellae. Clearance of the infection by as much as $97.8 \%$ when treatment was with $7.5 \mathrm{mg} / \mathrm{Kg}$ AT in AMS suggests that incorporating AT in AMS may help to reduce incidence of development of resistance by $S$. gallinarum against Ampicillin. The 2.2\% infection left, could be elliminated by immune mechanisms of the chicks.

The observation that when AMS is used to potentiat active drugs, subnormal doses produce better results than normal therapeutic doses has been consistent. Similar results have been obtained with AMS on Sulphadimidine against avian Coccidia [13], with AMS on Chloroquine phosphate against plasmodium [14] and with AMS on piperazine against helignosomoides bakeri [15]. By stabilizing drugs, AMS enhances their activities. So, normal doses could become toxic to treated animals. Toxicity from drugs leads to immunosupression. Immunosupression due to drug toxicity may have been responsible for the increased oocysts count per gramme of faeces, the increase in parasitaemia and the increased number of helminth eggs per gramme of faeces. It may also be responsible for the high bacterial titre in bile of treated chicks, observed in this study.

Use of lower doses of AT potentiated by AMS, to treat salmonellosis in food animals, has in addition to better bacterial clearance as demonstrated in this study, added advantages of reduction in cost of treatment and reduction in level of antibiotic residues in meat of treated animals.

AMS could not enhance ability of AT to inhibit grsowth of $S$. gallinarum, in vitro, but it significantly reduced the bacterial titre in bile of treated chicks. This suggests that mechanism by which the AMS enhanced antibacterial action of the antibiotic against the bacterium may not be by increasing its potency but by reducing rate of degradation of the drug. Vanderbilt [9] reported that AMS is a stabilizing agent. To stabilize means to protect against destruction. Brent et al. [6] had already observed that when high concentration of AT was retained in blood of treated animals, improved antibacterial effects resulted. So, what AMS does may be to protect drugs against degradation by metabolic processes so that high concentrations of the drugs are retained in the blood for longer periods, after treatment.

Salmonellosis is a major disease of both humans and animals in many parts of the world. Humanbeings could get infected if infected meat is consumed. Also, if bacterial infection is not adequatly cleared by an antibiotic treatment, the bacteria can develop resistance to the antibiotc. So, use of AMS to improve antibacterial activity of Ampicillin trihydrate, would help reduce infection rate of food animals and so reduce chances of transimission to humambeings. Clearance of upto $97.8 \%$ of the bacterial infection as achieved with $7.5 \mathrm{mg} / \mathrm{kg}$, Ampicillin stabilized with AMS in this study, could reduce chances of development of antibiotic resistance by Salmonella gallinarum. Also, the result suggests that AMS could be

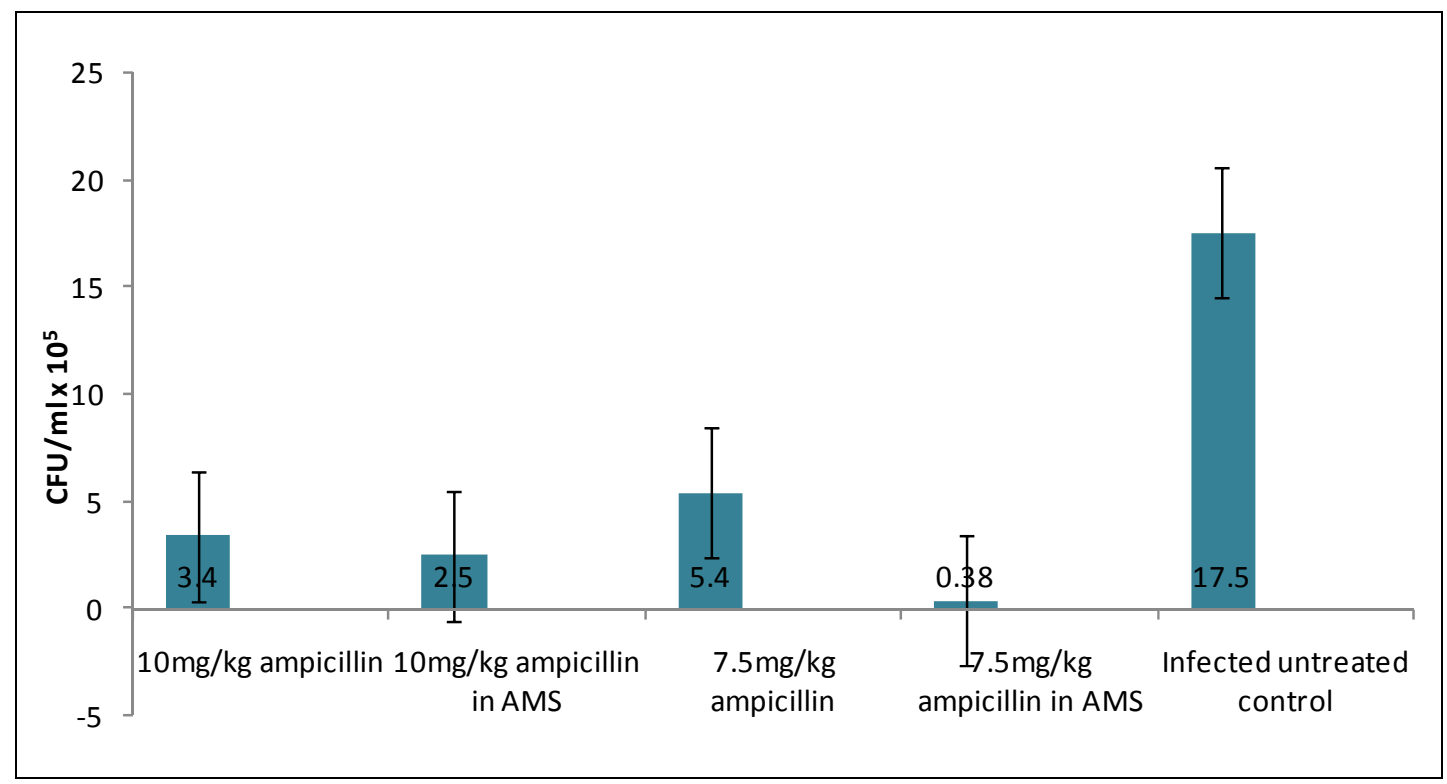

Figure 1. S. gallinarum CFU $\times 10^{5} / \mathrm{ml}$ in bile of infected chicks treated with Ampiccillin trihydrate-Aluminium Magnesium Silicate drug formulation. 
used to stabilize Ampicillin trihydrate and other antibiotics for more effective treatment of salmonellosis (typhoid fever) in humanbeings.

\section{REFERENCES}

[1] Crump, J.A., Luby, S.P. and Mintz, E.D. (2004) The global burden of typhoid fever. Bulletin of the World Health Organization, 82, 346-353.

[2] Klotchko, A. and Walace, M.R. (2009) Salmonellosis. http://www.emedicinemedscape.com/article/228174

[3] CDC (2009) Preliminary food net data on the incidence of infection with pathogens transmitted commonly through food-10 statea. MMWR Morbidity and Mortality Weekly Report, 59, 418-422.

[4] CDC (2010) Salmonellosis. MMWR Morbidity and Mortality Weekly Report 2009, 58, 25-29.

[5] Helms, M., Simonsen, J. and Molbak, K. (2004). Quinolone resistance is associated with increased risk of invasive illness or death during infection with Salmonella serotype Typhimurium. Journal of Infectious Diseases, 190, 1652-1654. doi:10.1086/424570

[6] Gunderson, B.W., Ross, G.H., Ibrahim, K.H. and Rotschafer, J.C. (2001) What do we really know about antibiotics pharmacodynamics? Pharmacotherapy, 21, 302S$318 \mathrm{~S}$.

[7] Aiello, S.E. (1998) Merck veterinary manual. 8th Edition, Merk and Co. Inc., Whitehouse Station.
[8] Wai, K.-N., Dekay, H.G. and Banker, G.S. (1996). Application of montmorrillonitse in tablet making. Journal of Pharmaceutical Sciences, 55, 1244-1248. doi:10.1002/jps.2600551116

[9] Vanderbilt, T.I. (1992). Veegum-The versatile ingredient for pharmaceutical formulations. Inc. Tecnical Literature.

[10] Schills, S. (2002) The use of clay in fight against effect of ammonia. http://www.mistalus.net

[11] Elmore, A.R. (2003) Cosmetics ingredients review experts panel's report. International Journal of Toxicology, 22, 37-102.

[12] Ezeibe, M.C.O. (2006) Admacine. Federal Republic of Nigeria. Patents and Design Act. Cap. 344. LDN. 1990. No. 16448.

[13] Ezeibe, M.C.O., Okafor, U.C., Okoroafor, O.N., Eze, J.I., Ngene, A.A., Animoke, P.C. and Mbuko, I.J. (2011) Effect of Aluminium-Magnesium Silicate on anticcocidial activity of sulphadimidin. Tropical Veterinarian, 29, 4144.

[14] Ezeibe, M.C.O., Elendu-Eleke, N.P., Okoroafor, O.N. and Ngene, A.A. (2012) Adjuvant effect of a synthetic Aluminium-Magnesium Silicate on chloroquine phosphate, against Plasmodium berghei. Health, 4, 448-451.

[15] Ezeibe, M.C.O., Dire, C.D., Anosa, G.N., Chikelu, O.N., Okoroafor, O.N., Okorie, O.K., Ngene, A.A., Idika, I.K., Ogunniran,T.M. and Ezeala, I.E. (2012) Efficacy of piperzine citrate, stabilized with Aluminium-Magnesium silicate, against Helignosomoides bakeri. Health (Accepted for Publicatio). 